\title{
Response to 2-Deoxy-D-glucose and to Glucagon in "Ketotic Hypoglycemia" of Childhood: Evidence for Epinephrine Deficiency and Altered Alanine Availability
}

\author{
Pierre C. Sizonenko, ${ }^{[49]}$ Lug Paunier, Michel B. Vallotton, Guy S. Cuendet, \\ Gaston Zahnd, and Errol B. Marliss
}

\begin{abstract}
Division of Endocrinology, Department of Pediatrics and Genetics; Division of Endocrinology, Clinical Biochemistry, and Fondation pour Recherches Médicales, Department of Medicine, University of Geneva School of Medicine, Geneva, Switzerland
\end{abstract}

\section{Extract}

The commonest clinical type of hypoglycemia in childhood presents as "ketotic hypoglycemia," a syndrome which typically remits spontaneously before adolescence. In young children with the severe form of this syndrome, deficient catecholamine secretion and, recently, decreased mobilization of gluconeogenic substrate (alanine) have been shown. The present study concerns five children with ketotic hypoglycemia, aged 2.5 to 9.5 years, and six control children, of similar ages. Each received (1) an infusion of 2-deoxy-D-glucose (2-DG) to test the catecholamine response and (2) intravenous glucagon before and after a 26-28-hr fast, to define possible difference in the response of substrates and hormones, with particular reference to alanine. In the control group, the infusion of $2-\mathrm{DG}, 50 \mathrm{mg} / \mathrm{kg}$ body wt over $30 \mathrm{~min}$, induced anxiety, hunger or thirst and sweating, as well as a sustained rise in plasma glucose from $78 \pm 5$ (mean \pm SEM) to $156 \pm 13.5 \mathrm{mg} / 100 \mathrm{ml}$ from $1-3 \mathrm{hr}$ after beginning the infusion. There was a transient rise in renin activity in plasma (PRA) from $2.0 \pm 0.5$ to a peak of $5.8 \pm 1.2 \mathrm{ng} / \mathrm{ml} / \mathrm{hr}$. By contrast, in the children with hypoglycemia, no clinical response was observed, and there was no change in either glucose in plasma, which remained at $77 \pm 6 \mathrm{mg} / 100 \mathrm{ml}$, or in $\mathrm{PRA}(1.3 \pm 0.3$ to $1.0 \pm 0.5 \mathrm{ng} / \mathrm{ml} / \mathrm{hr})$. After a period of unrestricted diet, and after an overnight fast, values of plasma glucose, insulin, glucagon, $\beta$-hydroxybutyrate, and alanine were the same in the two groups. In both groups intravenous glucagon, $30 \mu \mathrm{g} / \mathrm{kg}$, was followed by a comparable rise in glucose in plasma and immunoreactive insulin and a comparable fall in alanine in plasma. During the subsequent fast, glucose and insulin in plasma declined similarly. Ketonuria appeared at the same time and $\beta$-hydroxybutyrate in plasma rose to equivalent values. The response to a second glucagon infusion was smaller after fasting both as to glucose in blood and plasma insulin, but once again similar for control and hypoglycemia groups. However, the fall in alanine in plasma was significantly greater in the hypoglycemic group during fasting (to $200 \pm 13 \mu \mathrm{M}$ for the control group compared with $151 \pm 13 \mu \mathrm{M}$ for the hypoglycemia group, $P<0.05$ ) and at five time points $(10,30,60,90$, and $120 \mathrm{~min})$ after the second glucagon administration. Absence of hyperglycemic response to 2-DG in ketotic hypoglycemia suggests 
impaired catecholamine response. Further, after provocation by fasting and subsequent glucagon administration, the hypoalaninemia which resulted was more marked. Because epinephrine has been shown to raise alanine levels in plasma in man, it is hypothesized that a connection may exist between defective catechol secretion and alanine mobilization in ketotic hypoglycemia.

\section{Speculation}

Decreased availability of alanine in so-called ketotic hypoglycemia probably represents a defective metabolic system by which neoglucogenic substrates are not readily mobilized, rather than an absolute absence of substrate. One of the possible defective metabolic systems might be through the epinephrine secretion. However, the mobilizable pool of one of these neoglucogenic factors such as alanine could be small in the infants, and become bigger as muscle, which is a storage compartment of alanine, develops with age and puberty. If such is the case, it could be an explanation of the decrease of the frequency of attacks with age, generally at puberty.

\section{Introduction}

It has been shown that ketotic hypoglycemia [4], the most common form of hypoglycemia in childhood, is associated with a deficiency in excretion of epinephrine in urine in response to hypoglycemia which results from either the infusion of insulin or the administration of a ketogenic diet [16]. More recently, a deficiency of the availability of alanine and perhaps glutamine as substrates for gluconeogenesis has been shown in ketotic hypoglycemia [22, 26]. In order to investigate these two possible defects and correlate them, we have examined the response to 2-deoxy-D-glucose [31] and to glucagon infusion before and after a period of prolonged fasting. Comparisons were made between a group of children presenting with ketotic hypoglycemia and a group of control children of similar age.

\section{Methods}

\section{Subjects}

Five children, all males, aged 2 years 2 months- 8 years 9 months were investigated after clinical presentation with the criteria of ketotic hypoglycemia (Table I). The first hypoglycemic episode was documented at the age of 1 year 6 months-2 years 5 months. Hypoglycemia occurred in the morning. Since the first episode, each patient was admitted several times for hypoglycemic convulsions and coma. In all instances ketonuria was associated with hypoglycemia. The last episode had occurred no more than 6 months previous to the time of study. Two were twins of whom the siblings were unaffected. Patient $C A$ was a genetically identical twin to $C P$. One of the patients was mentally retarded. None received any treatment for more than 2 months before the admission, except for a diet which consisted of frequent meats. At the time of study, heights and weights were in the lower percentiles in three of the five. Growth hormone determinations during either an insulin-induced hypoglycemia or arginine tolerance test were normal. Metyrapone administration induced a normal rise of 11-deoxycorticosteroids [17]. Six children (five males and one female), aged 3 years 5 months -8 years 7 months were admitted to the Department of Pediatrics for evaluation of a supposed but unproved abnormality of carbohydrate metabolism (except in two, the twin brothers of patients $C A$ and $K Y)$. No clinical endocrine abnormalities were apparent nor revealed by tests of growth hormone, adrenocorticotropic hormone (ACTH), and insulin secretion. No hypoglycemic episode was observed in any of them. Hereafter, in this study, they are referred to as control subjects.

\section{Study Protocol}

All of the tests were performed after informed parental consent. All children received a regular hospital diet, which consisted of $65 \%$ carbohydrate, $12 \%$ fat, and $23 \%$ protein, during the few days preceding and during the intervals between the tests.

First, they were submitted to a 2-DG infusion performed after an overnight fast. The children were recumbent for $12 \mathrm{hr}$ before, and during the whole procedure. Sterile 2-DG [42], $50 \mathrm{mg} / \mathrm{kg}$ body wt, was diluted 
Table I. Clinical data

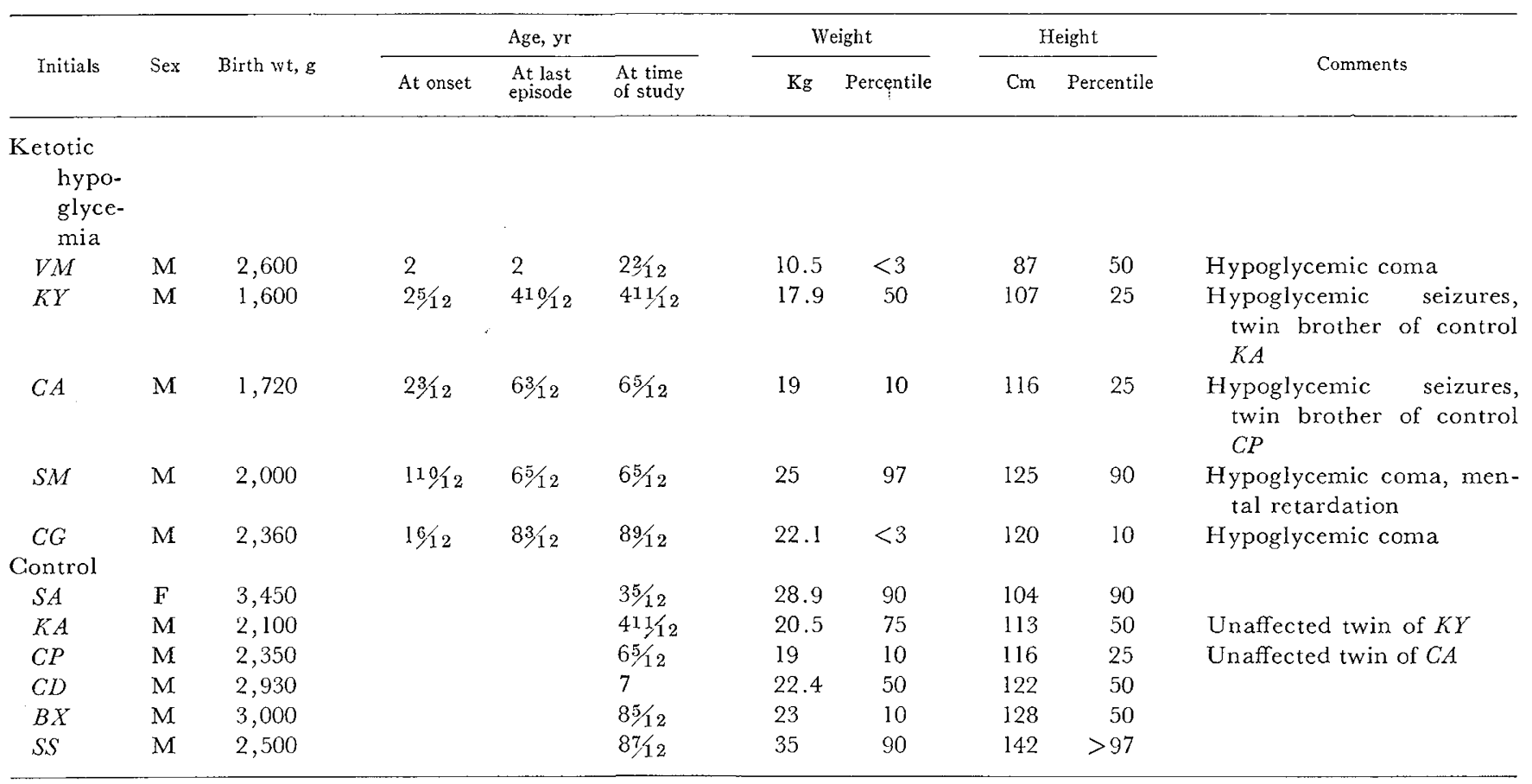

in a total volume of $50-100 \mathrm{ml}$ saline and infused during $30 \mathrm{~min}$. Control blood samples for glucose in plasma, PRA, cortisol, and immunoreactive glucagon in some cases were obtained at $30 \mathrm{~min}$ and immediately before the infusion of 2-DG and every $30 \mathrm{~min}$ up to 180 min after the infusion was started.

Second, both groups were submitted, $48 \mathrm{hr}$ later, to the following procedure: after an overnight fast and control blood sampling, at $8 \mathrm{AM}, 30 \mu \mathrm{g} / \mathrm{kg}$ of body weight of glucagon [43] was injected intravenously in order to assess glucose, immunoreactive insulin, and alanine responses. A meal consisting of $65 \%$ carbohydrate, $23 \%$ protein, and $12 \%$ fat was administered at noon, then a 26-28-hr fast was started. During the fasting period, the level of glucose in plasma was monitored and the presence of ketone bodies in the urine was tested at regular intervals. In seven instances, blood samples were drawn before and at the end of the fasting period for $\beta$-hydroxybutyrate determination and in all subjects samples were drawn for plasma cortisol and immunoreactive glucagon. A second intravenous injection of glucagon was thereafter administered at the same dosage in order to evaluate the plasma glucose, insulin, and alanine responses. All blood samples were obtained by an indwelling needle in an antecubital vein, through which a slow infusion of saline was maintained during the whole procedure. All of the samples were immediately put on ice and centrifuged at $4^{\circ}$; plasma was kept frozen at $-20^{\circ}$ until assay. Levels of significance of differences were established using the. Wilcoxon rank test or the Student $t$ test.

\section{Estimation of Hormones and Substrates}

Determinations of glucose in plasma were performed using the "autoanalyzer" ferricyanide method [2], except for glucose determinations during the 2-DG infusion. The orthotoluidine technique [14] was employed because 2-DG does not influence this method. Activity of renin in plasma was determined by radioimmunoassay which measured the production of angiotensin I released during incubation [34]. Glucagon in plasma was assayed by radioimmunologic technique [33] using a specific antipancreatic glucagon serum (30 K) [44] and cortisol by the protein-binding competitive method of Murphy [25]. For the determinations which did not involve 2-DG infusion, alanine in plasma was estimated by a fluorimetric method using alanine dehydrogenase [45] on samples deproteinized with an equal volume of $8 \%$ perchloric acid [39]. Specificity of the assay was high. The following amino acids, aspartate, threonine, serine, proline, glutamic acid, glycine, cystine, methionine, isoleucine, leucine, tyrosine, phenylalanine, lysine, histidine, and arginine, were tested 


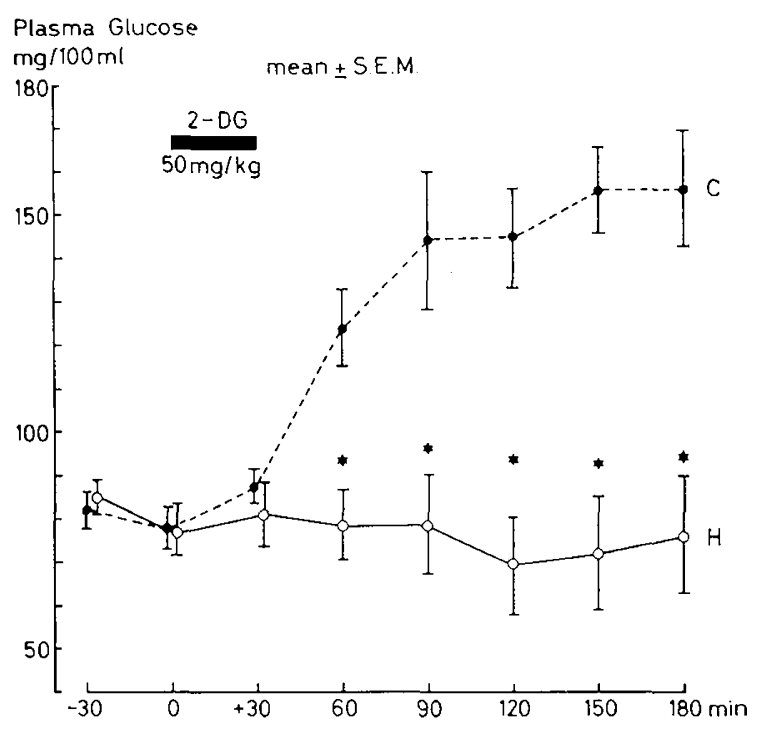

Fig. I. Mean levels of glucose in plasma before and after administration of 2-deoxy-D-glucose (2-DG) in control $(C)$ and hypoglycemic $(H)$ children. * $P<0.05$.

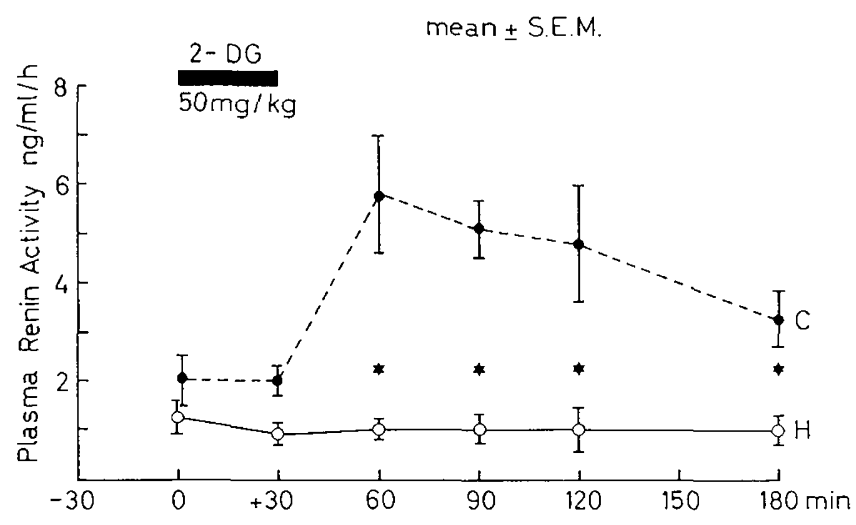

Fig. 2. Mean level of renin activity in plasma during and after administration of 2-deoxy-D-glucose $(2-D G)$ in control $(G)$ and hypoglyccmic $(H)$ children. *: $P<0.05$.

and did not react in the assay. Intra- and interassay variation coefficients for the alanine determination were $2 \%$ and $4 \%$, respectively. $\beta$-Hydroxybutyrate was assayed by a standard enzymatic fluorimetric method [40] on similarly deproteinized samples. Ketone bodies in the urine were detected using the Acetest. Insulin in plasma was measured by a double antibody radioimmunoassay $[12,23]$.

\section{Results}

\section{2-Deoxy'-D-glucose Infusion}

All control children had clinical manifestations which suggested increased epinephrine secretion: pal- lor, sweating, hunger or thirst, or both. No such symptoms occurred in the ketotic hypoglycemic children. In the control group, a rise of glucose in blood (Fig. 1) was observed after the infusion of 2-DG. Mean plasma values increased markedly $30 \mathrm{~min}$ after the cessation of 2-DG from $78 \pm 5$ (mean $\pm \mathrm{sEM}$ ) to $124 \pm 9 \mathrm{mg} / 100$ $\mathrm{ml} 60 \mathrm{~min}$ after, and to $156 \pm 14 \mathrm{mg} / 100 \mathrm{ml} 180 \mathrm{~min}$ after. Among the hypoglycemic children no rise of glucose in plasma was detected $(77 \pm 6$ at zero time, $76 \pm$ $14 \mathrm{mg} / 100 \mathrm{ml}$ at $180 \mathrm{~min}$ ). Mean values obtained in this group at $60,90,120,150$, and 180 min were signifcantly different from the control group values $(P<$ $0.05)$. PRA increased after the infusion of 2-DG in all the control children (Fig. 2). Mean values were $2.0 \pm$ 0.5 at $0 \mathrm{~min}, 5.8 \pm 1.2$ at $60 \mathrm{~min}, 5.1 \pm 0.6$ at $90 \mathrm{~min}$, $4.8 \pm 1.2$ at $120 \mathrm{~min}$, and $3.3 \pm 0.6 \mathrm{ng} / \mathrm{ml} / \mathrm{hr}$ at 180 min. In the hypoglycemic patients, no increase of PRA was detected. Mean values remained identical (from $1.3 \pm 0.3$ to $1.0 \pm 0.2 \mathrm{ng} / \mathrm{ml} / \mathrm{hr}$ at $60 \mathrm{~min}, 1.0 \pm 0.3 \mathrm{at}$ $90 \mathrm{~min}, 1.0 \pm 0.5$ at $120 \mathrm{~min}$, and $1.0 \pm 0.3$ at 180 $\mathrm{min})$. Mean values of the latter group were thus significantly different from the control group at times 60 , 90, 120, and $180 \mathrm{~min}(P<0.05)$. Levels of immunoreactive glucagon in plasma during and after the infusion of 2-DG decreased in two control children and showed no consistent change in two. In the hypoglycemic group the three patients for whom data are available also showed no change after the infusion of 2-DG (Fig. 3). In no instance was there a rise in immunoreactive glucagon. Although a wide dispersion of values for cortisol in plasma was observed (Fig. 4), there were similar cortisol levels in both groups with a rise at 90 and $120 \mathrm{~min}$ in the control group. However, responses in both groups were not significantly different.

\section{Glucagon Administration and Fasting.}

After the first glucagon infusion, the level of glucose in plasma rose in both groups of children (Figs. 5 and 6). During the 26-28-hr fast ketone bodies appeared between 12 and $21 \mathrm{hr}$ in the urine of both control and hypoglycemic children. During the same period, concentrations of glucose in plasma decreased in a similar fashion (Table II). After the second infusion of gluca. gon, there was a slight rise of glucose in plasma in both groups. In the three instances in which a some. what greater hyperglycemic response was observed, the preinfusion glycemia was the highest in both groups In four hypoglycemic and five control children, $\beta$-hy. droxybutyrate levels before the fast were identical and increased similarly in both groups during the fast 

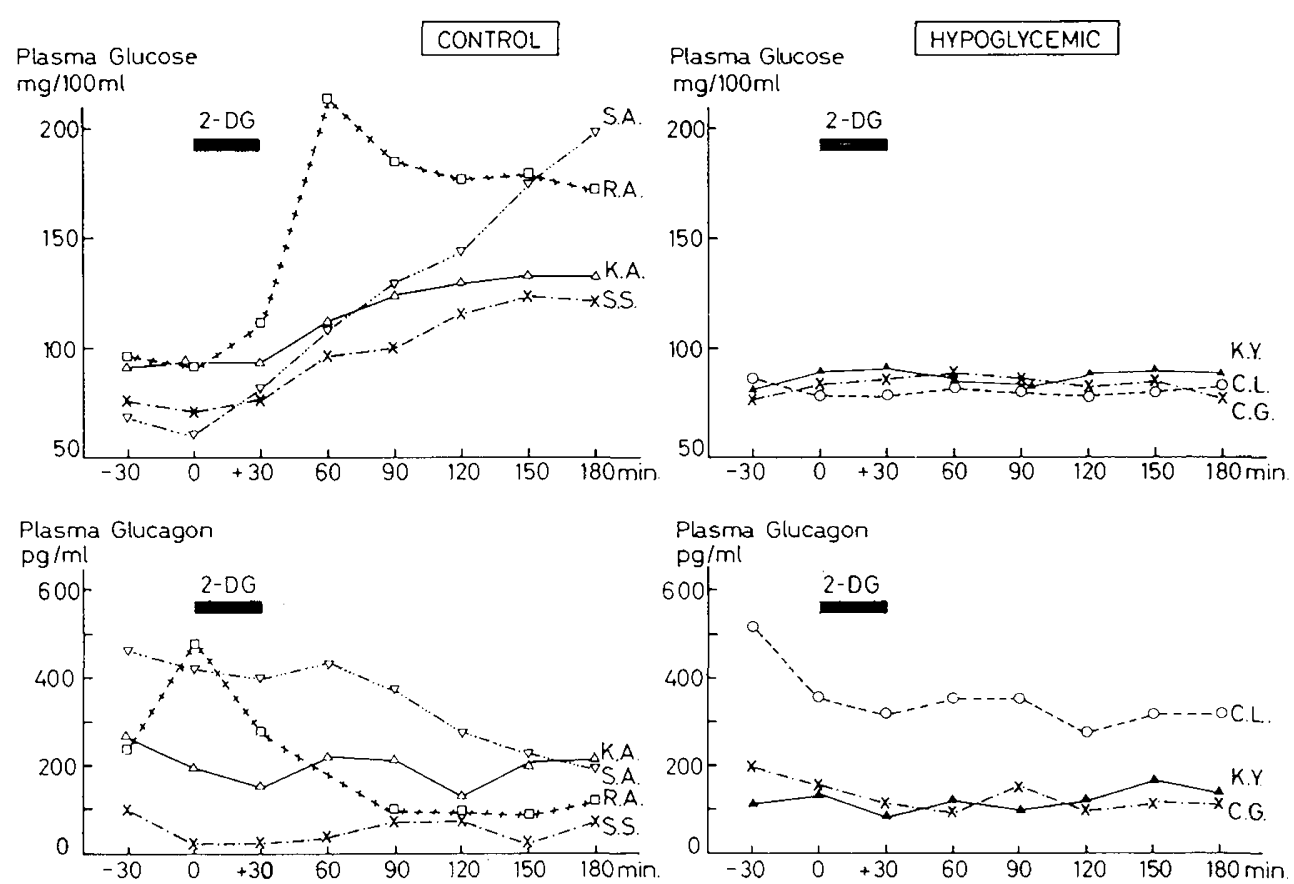

Fig. 3. Glucose in plasma and immunoreactive glucagon concentrations during and after administration of 2-deoxy-D-glucose (2-DG) in four control subjects and three hypoglycemic children.

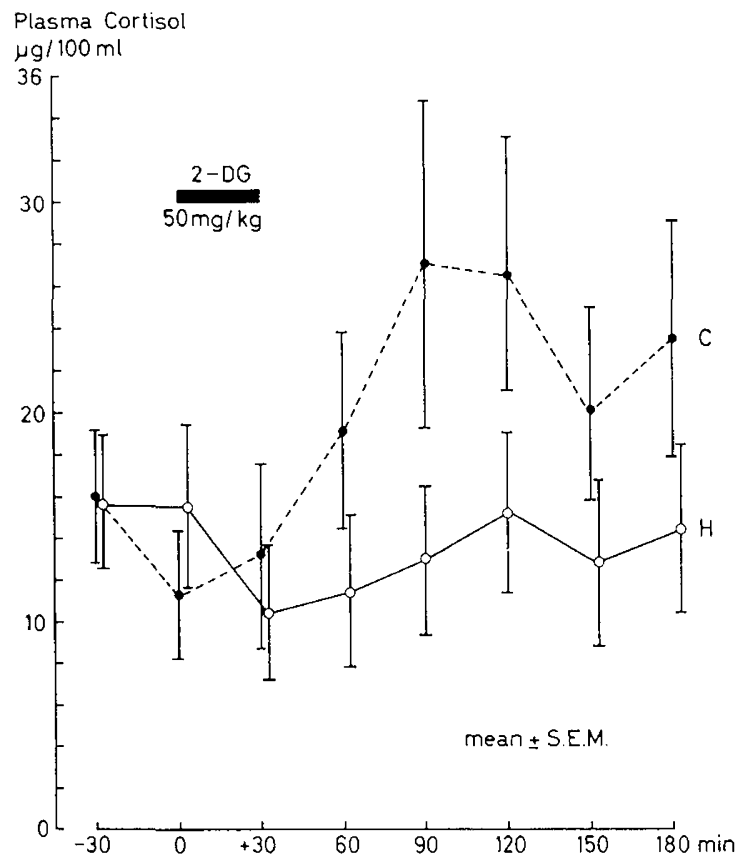

ig. 4. Mean levels of cortisol in plasma before and after adminstration of 2-deoxy-D-glucose (2-DG) in control $(C)$ and hypoglyemic $(H)$ children.

Nean $\beta$-hydroxybutyrate levels were not different Table II). Cortisol levels increased more markedly in he hypoglycemic group than in the control group
(Table II). Responses of insulin in plasma to the first glucagon injection were similar in both groups (Fig. 7). They were comparatively reduced when glucagon was injected at the end of the fasting period. Serum glucagon concentrations rose to a similar level at the end of the fasting period in both groups (Table II).

Mean levels of alanine in plasma appeared to decrease slightly during the first glucagon test in both groups, without any statistically significant difference, however, when compared to zero time values (Fig. 8). Mean concentration of alanine in plasma at the end of the fasting period was significantly lower in the hypoglycemic group $(P<0.05)$. After the glucagon administration following the 26-28-hr fast, mean alanine levels remained identical in the control group, whereas they decreased slightly in the hypoglycemic group. Mean alanine values for the hypoglycemic children observed at times 10, 30, 60, 90, and $120 \mathrm{~min}$ after glucagon were significantly different from the ones of the control group (at $P$ of $<0.05$ or $<0.01$ ).

\section{Discussion}

The syndrome currently identified as ketotic hypoglycemia was described by Colle and Ulstrom [4] in children who presented with concurrent ketosis and hypoglycemia and in whom hypoglycemia could be induced 


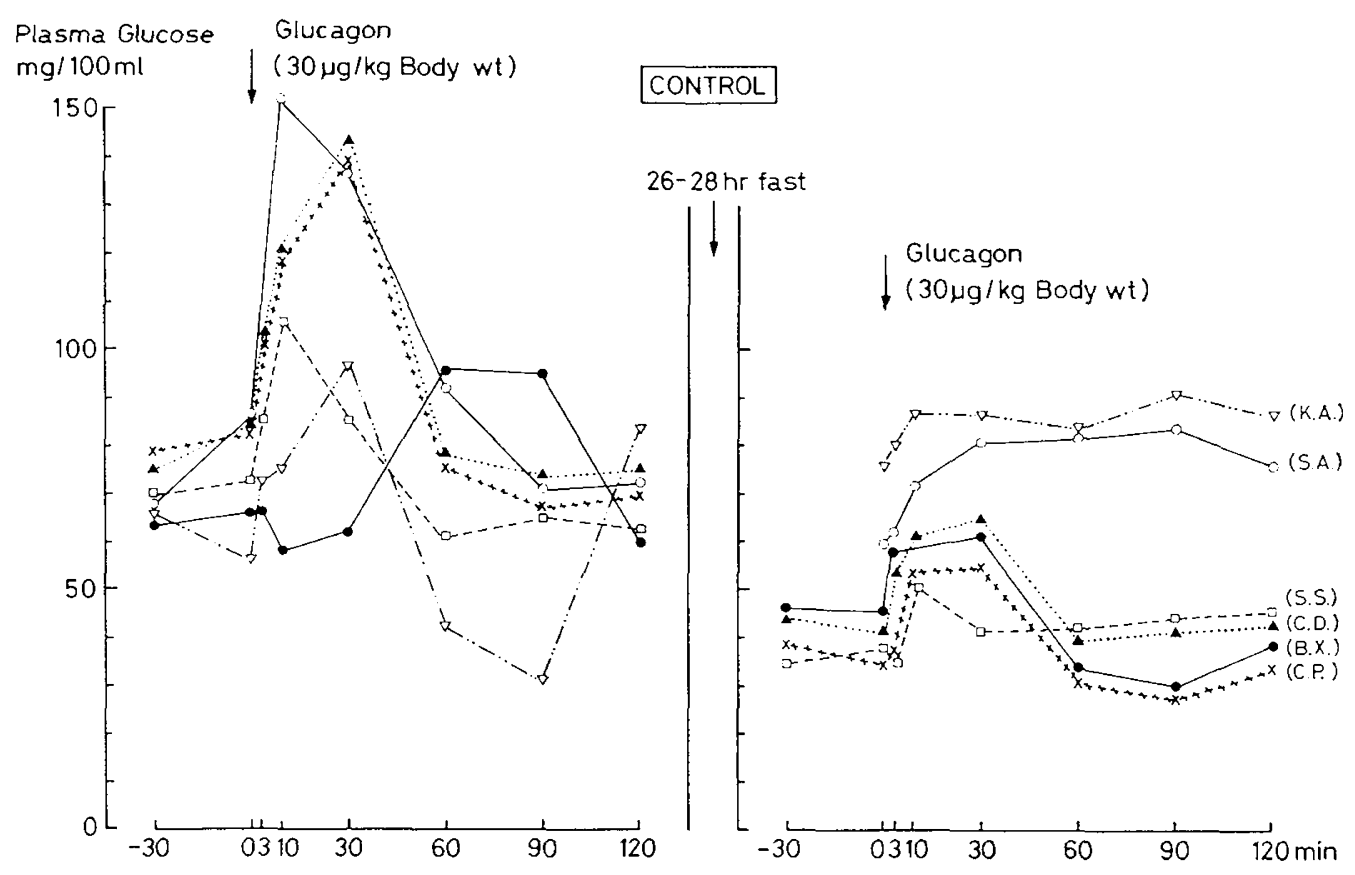

Fig. 5. Plasma concentrations in glucose in control children during the glucagon tests, before and after the 26-28-hr fasting period.

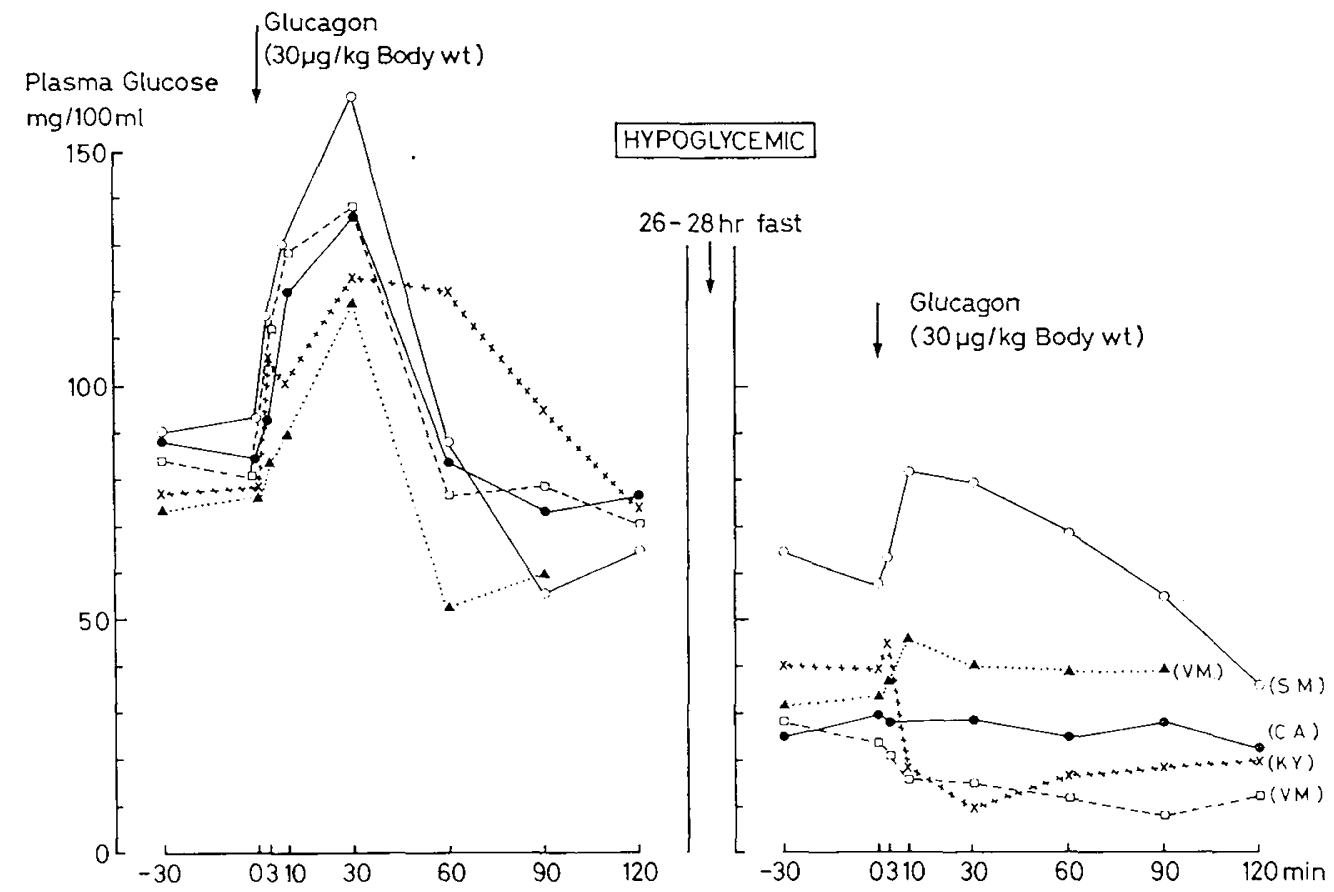

Fig. 6. Plasma concentrations in glucose in hypoglycemic children during the glucagon infusions before and after the 26-28-hr fasting period.

by a ketogenic diet. It is now recognized that the coincidence of ketosis with hypoglycemia may occur in a number of disorders due to specific enzyme defects [27]. However, in the majority of cases, no such specific etiologic mechanism has been identified. The subjects of the present study conform to the clinical pattern of such a syndrome although homogeneity of age is not as great as when compared with other studies [26]. The 
Table II. Effect of 26-28-hr fasts on mean concentrations ( \pm SEM) of plasma hormones and substrates

\begin{tabular}{|c|c|c|c|c|c|c|}
\hline \multirow{2}{*}{ Hormone or substrate } & \multicolumn{3}{|c|}{ Before fast } & \multicolumn{3}{|c|}{ After fast } \\
\hline & Control & Hypoglycemic & $P^{1}$ value & Control & Hypoglycemic & $P^{1}$ value \\
\hline Glucose, $\mathrm{mg} / 100 \mathrm{ml}$ & $76 \pm 5$ & $84 \pm 3$ & NS & $49 \pm 6$ & $35 \pm 5$ & NS \\
\hline Alanine, $\mu \mathrm{M}$ & $229 \pm 21$ & $250 \pm 35$ & NS & $200 \pm 13$ & $151 \pm 13$ & $<0.05$ \\
\hline Cortisol, $\mu \mathrm{g} / 100 \mathrm{ml}$ & $11.4 \pm 1.9$ & $10.5 \pm 1.4$ & NS & $14.8 \pm 2.2$ & $30.4 \pm 7.0^{2}$ & $<0.05$ \\
\hline Insulin, $\mu \mathrm{U} / \mathrm{ml}$ & $4.4 \pm 0.8$ & $5.6 \pm 2.2$ & NS & $1.4 \pm 0.4$ & $2.9 \pm 1.4$ & NS \\
\hline
\end{tabular}

I $P$ value between the control and the hypoglycemic group mean concentrations. NS : not significant.

${ }^{2}$ Significantly different from mean concentrations observed before the fast in the hypoglycemic group $(P<0.05)$.

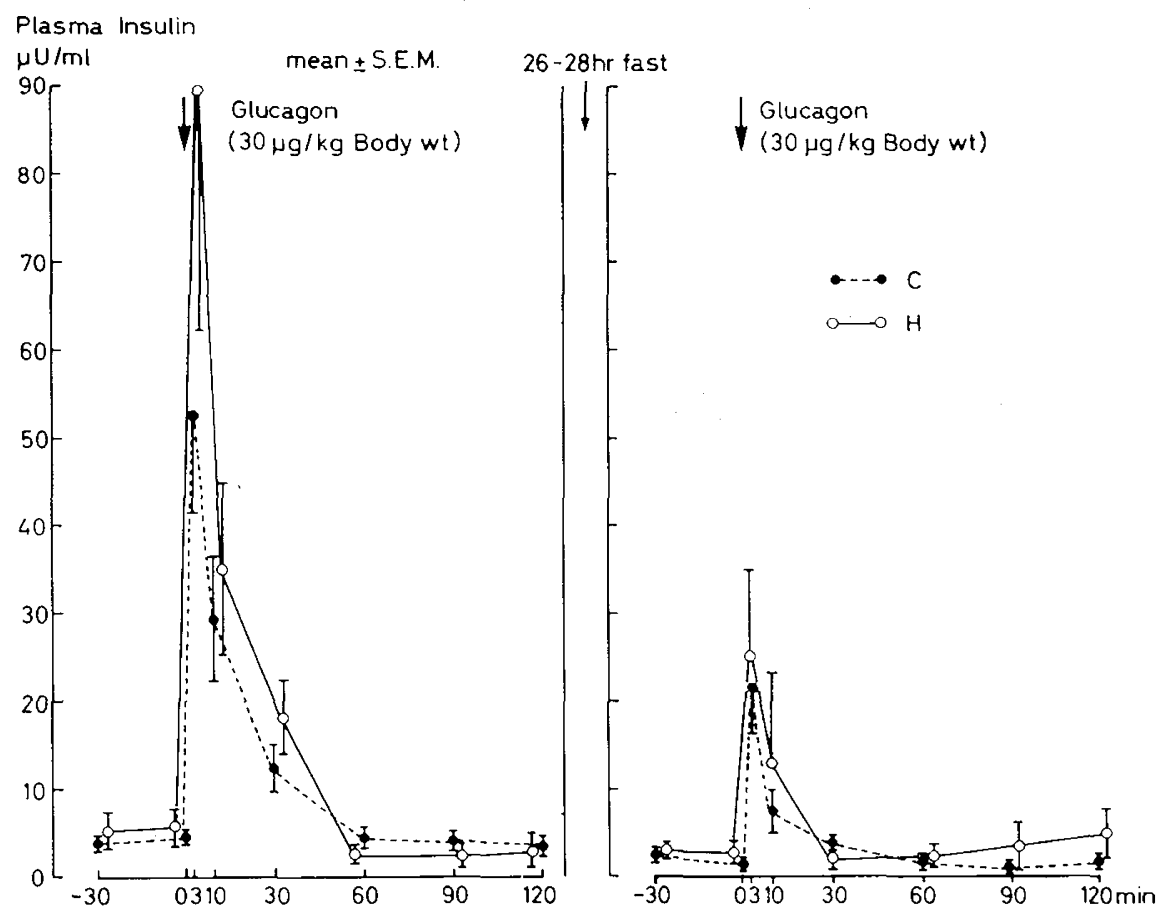

Fig. 7. Mean insulin responses in plasma to glucagon before and after the 26-28-hr fasting period in control $(C)$ and hypoglycemic $(H)$ children.

attacks were sporadic, occurred after a period of food deprivation, and in all instances there was associated ketonuria. Fasting plasma glucose was normal between the hypoglycemic episodes, and hyperinsulinism was absent. Exogenous glucagon induced a normal rise of glucose in plasma. The onset was between 18 and 30 months of age; all patients were males. Low birth weight was present in all, and three were twins. All were small and thin for their age except patients $K Y$ and $S M$. Although it is known that the frequency of attacks decreases with age, generally disappearing by puberty, these patients experienced at least one episode during the 6 months preceding the studies reported. In one case, an episode occurred after the study was performed.

A defective adrenal medullary response has previously been identified in such patients. Köffler et al. [16] demonstrated a deficiency in excretion of epinephrine in the urine in response to hypoglycemia which results from either the infusion of insulin or the administration of ketogenic diet. We have used 2-DG in the present study as a means of defining the responsiveness of pathways involved in epinephrine secretion. Several lines of evidence suggest that 2-DG acts on the nervous system centers sensitive to circulating glucose concentration. This glucose analogue is known to act 


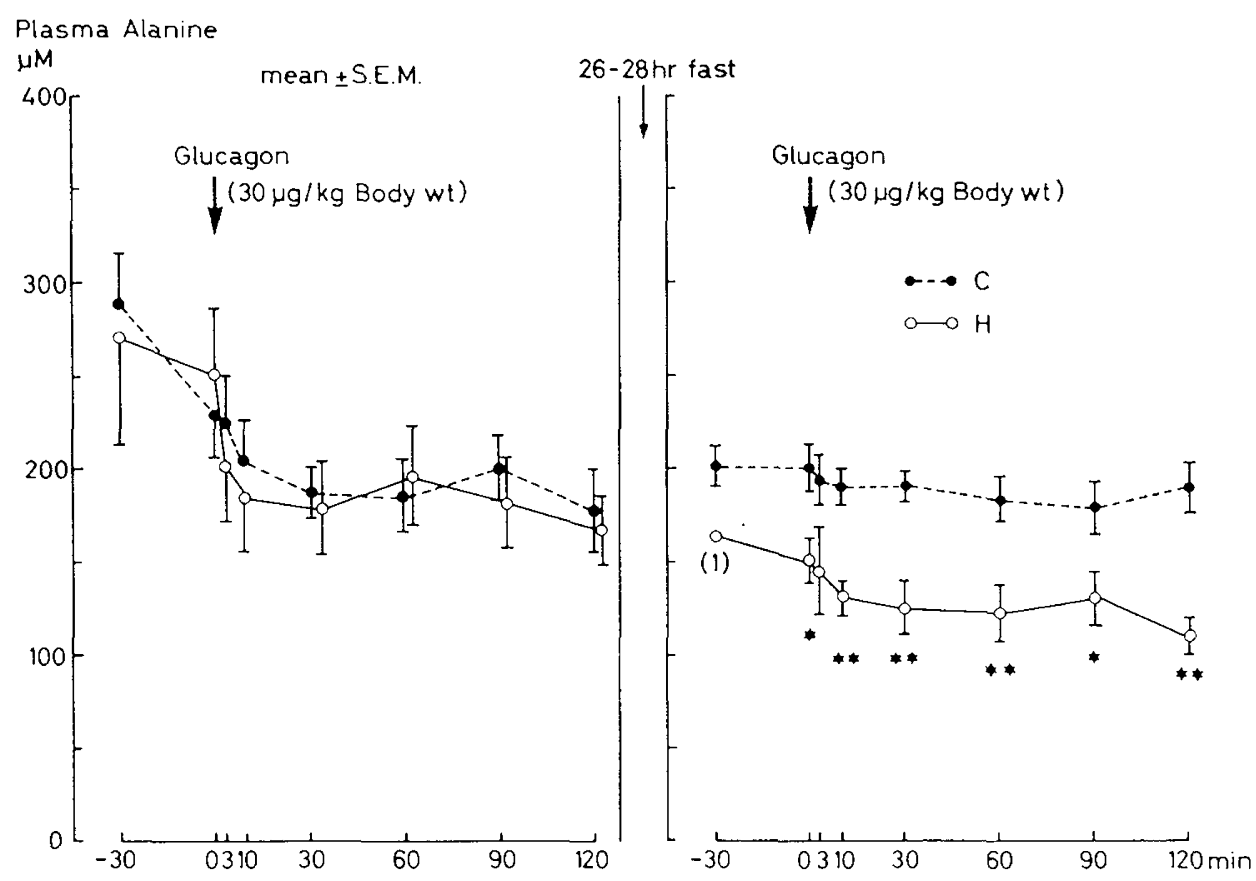

Fig. 8. Mean concentrations of alanine in plasma during the first (after overnight fast) and the second (after 26-28-hr fast) glucagon administrations. (1) : plasma of one case only was assayed; ${ }^{*} P<0.05$; ${ }^{*}: P<0.01$, comparisons between groups for a given time point; $C$ : control children; $H$ : hypoglycemic children.

on other cell types by blocking glucose metabolism at the glucose 6-phosphate isomerase step [38], hence inducing intracellular glucopenia. Such an effect would be expected to result in activation of neural pathways, which would result in epinephrine discharge, inasmuch as adrenal medullary cells are not directly responsive to hypoglycemia [29]. The secretion of catecholamines has been examined after 2-DG infusion in man: the increase observed in normal subjects [18, 28, 36] did not occur in Addison's disease of tuberculous origin $[28,36]$ or after thoracolumbar sympathectomy [36]. In normal subjects the catecholamine for which secretion was augmented was epinephrine $[28,36]$. In those instances in which epinephrine secretion was stimulated, 2-DG induced hyperglycemia, presumably primarily by catecholamine stimulation of liver glycogenolysis.

In the present study, activity of renin in plasma has been used as a further index of epinephrine secretion. Both in man $[11,28]$ and experimental animals $[30$, 35 ], renin release has been shown with activation of the sympathetic nervous system.

Striking differences were observed in the responses to 2-DG in control and affected subjects. The control subjects showed clinical manifestations suggestive of epinephrine secretion, whereas virtually no such reac- tions occurred in the hypoglycemic group. Furthermore, the controls showed an unequivocal rise in both plasma glucose and renin activity, again absent in the hypoglycemic children. Because 2-DG has been shown to stimulate pancreatic glucagon secretion in dogs [24], it was considered that the different glycemic responses could relate to differential glucagon responsiveness. However, this was ruled out on the basis of the absence of a rise in glucagon levels in both groups after 2-DG. The absence of glucagon rise implies, in addition, that the hyperglycemia seen in the control subjects was mediated directly by epinephrine action on the liver, rather than by catecholamine stimulation of glucagon secretion $[15,21]$.

The data suggest that children affected with ketotic hypoglycemia suffer from an inability of adrenal medullary regulatory centers to detect hypoglycemia or intracellular glucopenia and/or respond to the phenomenon. Anatomic localization of the defect at the level of the hypothalamus, brain stem, peripheral autonomic nervous system, or adrenal medulla is not possible by the approach used. Such an interpretation is consistent with previous findings in children with ketotic hypog:lycemia described by Köffler et al. [16] and the evidences for adrenal medullary unresponsiveness to induced hypoglycemia presented by Broberger and 
Zetterstrom [1] and confirmed by many authors [3, 20]. That the defect lies specifically in pathways concerned with epinephrine secretion and is not generalized to all hormone systems responsive to hypoglycemia is suggested by the responses of cortisol, indistinguishable in the two groups [31]. A different ACTH response to cellular glucopenia was demonstrated in young children with severe brain damage and with absent adrenal medulla response to insulin-induced hypoglycemia, contrary to present findings [32]. The normal cortisol levels observed in our study have further significance in that cortisol influences the methylation of norepinephrine to epinephrine because phenylethanolamine- $N$-transferase is dependent on the amount of glucocorticoid present in the adrenal medulla [13,41]. The identical cortisol responses to 2-DG thus render unlikely a decreased activity of phenylethanolamine- $N$-transferase related to altered cortisol secretion.

The response of circulating hormones and substrates to glucagon infusion and to fasting demonstrated rather subtle differences between the groups. No difference in glucose, insulin, $\beta$-hydroxybutyrate, or alanine in plasma was observed before or after glucagon administration after an overnight fast. In both groups, the prolonged fasting period was followed by a similar rate of fall of glucose in plasma. Ketone bodies appeared in the urine at the same time during fasting and $\beta$-hydroxybutyrate rose to comparable plasma levels. This differs from the findings of Colle and Ulstrom [4] and Pagliara and co-workers [26], who demonstrated a more rapid and significant decrease in glucose in blood and increase of $\beta$-hydroxybutyrate when hypoglycemic children were studied with a ketogenic diet or fasting. These differences may be attributable to the generally greater age of the present patients (who were probably closer to the age of spontaneous remission of the disease). Responses of glucose and insulin to the second glucagon administration after prolonged fasting in the two groups were similar. However, the increments in both glucose and insulin were greatly attenuated when compared with those obtained after the first glucagon injection. Cortisol levels in the hypoglycemic group increased more than in the control group during the prolonged fasting. During this period, levels of glucagon in plasma rose similarly in both groups. Prolonged fasting induced a greater fall of plasma alanine in the ketotic hypoglycemic subjects. In addition, the values after second glucagon administration did not change in the control group, but did in the hypoglycemic children. The greater fall cluring fasting corresponds to the recent findings of Pagliara and collaborators [26] and Micka et al. [22].

The greater hypoalaninemia after $26-28 \mathrm{hr}$ of fasting, in the presence of comparable levels of glucose insulin, and glucagon in plasma in the two groups, and, in the presence of higher concentrations of cortisol in plasma in the hypoglycemic group, cannot be accounted for by the data presented. Alanine has been demonstrated clearly to be a typical glucogenic amino acid, whose availability in fasting $[7,8]$ and in exercise [9] may be rate limiting for gluconeogenesis.

Changes in circulating levels of alanine reflect alteration either in their availability from peripheral sources or in the rate of their disposal, primarily by hepatic extraction (or both). The fall in alanine levels after glucagon administration probably represents in part stimulation of hepatic uptake for gluconeogenesis [8]. High levels of cortisol in plasma were presumably unable to prevent hypoalaninemia by increasing alanine release from muscle, although pharmacologic doses of cortisone were able to prevent the occurrence of hypoalaninemia and of hypoglycemia [26].

A role for circulating epinephrine levels in regulations of peripheral output of alanine has been suggested by Weisswange et al. [37]. Infusion of epinephrine in man induced a rise in alanine in plasma during a metabolic state characterized by hyperglycemia and low insulin levels, i.e., in which hepatic alanine uptake would be expected to be increased. Hence, a link between the defective epinephrine responses suggested in these cases of ketotic hypoglycemia, and decreased alanine mobilization may exist. These facts would suggest a synergistic action of both epinephrine and cortisol on the alanine release from the muscle at physiologic levels.

A direct role for ketone bodies themselves has been suggested in the occurrence of hypoglycemia [19, 26] and the mediation of muscle amino-acid release [5]. However, in the absence of difference in ketone levels, it would be necessary to postulate increased muscle sensitivity to ketones if such a mechanism was contributory.

The mechanism of disturbed epinephrine response to 2-DG remains unexplained. However, in a recent study [10] in which adrenal vein epinephrine levels were examined in response to insulin hypoglycemia, it was found that intracarotid infusion of $\beta$-hydroxybutyrate inhibited the epinephrine response to hypoglycemia. Drenick and co-workers [6] have furthermore shown no increase in catecholamine excretion after insulin-induced hypoglycemia in prolonged fasted 
(and thus hyperketonemic) man. Such data suggest that the appropriate brain center responsive to hypoglycemia no longer "recognizes" this state when provided with an alternate energy substrate in the form of ketone bodies. Thus, if in ketotic hypoglycemia such a center were either insensitive to hypoglycemia or excessively sensitive to ketones, a defective adrenal discharge might occur. The absence of response to 2-deoxyD-glucose would favor the first possibility. It seems likely that ketotic hypoglycemia is a heterogenous syndrome, both with respect to differences in manifestations with age, and perhaps to pathophysiologic mechanisms. In some cases, it is probably due to a decreased availability of alanine and probably other important gluconeogenic substrates. A decreased activity of liver enzyme involved in glycogenolysis and/or the gluconeogenesis is rendered less probable by the previous studies which demonstrated that infusions of alanine prevented the hypoglycemia [26]. In our patients the decreased availability of alanine was demonstrated only when gluconeogenesis was stimulated by prolonged fasting. Because epinephrine has been shown to raise the level of alanine in plasma, the hypothetic mechanism proposed is based on evidence for deficient adrenal medullary responsiveness and consequent defective alanine availability. This may be applicable only to a particular group of patients with ketotic hypoglycemia, and may require definitive testing in order to be validated.

\section{Summary}

In five children presenting with "ketotic hypoglycemia" a defective rise of glucose in plasma and renin activity was observed after infusion of 2-deoxy-b-glucose, which suggested an impaired secretion of epinephrine. After a prolonged fast, the same affected children demonstrated a diminished level of alanine in plasma, when compared with a group of control children who were responsive to 2-deoxy-D-glucose.

A link may exist between the defective epinephrine secretion and alanine mobilization in "ketotic hypoglycemia," inasmuch as epinephrine has been shown to raise levels of alanine in plasma in man.

\section{References and Notes}

1. Broberger, O., AND Zetterstrom, R.: Hypoglycemia with an inability to increase the epinephrine secretion in insulininduced hypoglycemia. J. Pediat., 56: 215 (1961).

2. Brown, M. E.: Ultra-microsugar determinations using 2,9- dimethyl-1,10-phenanthroline hydrochloride (neocupreine). Diabetes, 10: 60 (1961).

3. Brunjes, S., Hodgman, J., Nowack, J., and John, V. J., Jr.: Adrenal medullary function in idiopathic spontaneous hypoglycemia of infancy and childhood. Amer. J. Med., 34: 168 (1963).

4. Colle, E., and Ulstrom, R. A.: Ketotic hypogiycemia. J. Pediat., 64: 632 (1964).

5. Cuendet, G. S., Loten, E., Wollheim, C. B., Rabinovitch, A., ANd Marliss, E. B.: Protein-conserving effect of fat-derived substrates. Clin. Res., 20: 942 (1972).

6. Drenick, E. J., Alvarez, L. C., Tamasi, G. C., and Brickman, A. S.: Resistance to symptomatic insulin reactions after fasting. J. Clin. Invest., 51: 2757 (1972).

7. Felig, P., Owen, O. E., Wahren, J., and Cahill, G. F., Jr.: Aminoacid metabolism during prolonged starvation. J. Clin. Invest., 48: 584 (1969).

8. Felig, P., Pozersky, T., Marluss, E., and Cahill, G. F., Jr.: Alanine: Key role in gluconeogenesis. Science, 67: 1003 (1970).

9. Felig, P., and Wahren, $J$.: Amino acid metabolism in exercising man. J. Clin. Invest., 50: 2703 (1972).

10. Flatt, J. P., Blackburn, G., and Randers, G.: Effects of ketone body infusion in hypoglycemic reaction in fed dogs (Abstract). Fed. Proc., 3.1: 434 (1972).

11. Gordon, R. D., Küchel, O., Liddle, G. W., ANd Island, D. P.: Role of the sympathetic nervous system in regulating renin and aldosterone production in man. J. Clin. Invest., 45: 599 (1967).

12. Hales, C. N., and Randle, P. J.: Immunoassay of insulin with insulin-antibody precipate. Biochem. J., 88: 137 (1963).

13. Hung, W., And Mrgeon, C. J.: Hypoglycemia in a two-year-old boy with adrenocorticotropic hormone (ACTH) deficiency (probably isolated) and adrenal medullary unresponsiveness to insulin-induced hypoglycemia. J. Clin. Endocrinol., 28: 146 (1968).

14. Hyvirinen, A., AND NikKLA, E.: Specific determination of blood glucose with o-toluidine. Clin. Chem. Acta, 7: 140 (1962).

15. Iverson, J.: Adrenergic receptors for the secretion of immunoreactive glucagon and insulin from the isolated, perfused canine pancreas. Diabetologia, 7: 485 (1971).

16. Köffler, H., Schubert, W. K., ANd Hug, G.: Sporadic hypoglycemia: Abnormal epinephrine response to the ketogenic diet or to insulin. J. Pediat., 78: 448 (1971).

I7. Kohlberg, I. J., Doret, A. M., PAunier, L. and Sizonenko, P. C.: Assessment of the pituitary adrenal cortex axis in children by a single dose metyrapone test. Helv. Paediat. Acta, 27: 437 (1972).

18. Laszlo, J., Harlan, W. R., Klein, R. F., Kirshner, N., Estes, E. H., AND Bogdonoff, M.D.: The effect of 2-deoxy-D-glucose infusions on lipid and carbohydrate metabolism in man. J. Clin. Invest., 40: 171 (1961).

19. LoRIDAN, L., AND SENIOR, B.: Effects of infusion of ketones in children with ketotic hypoglycemia. J. Pediat., 76: 69 (1970).

20. Madsen, A.: Spontaneous hypoglycemia with convulsions and deficient adrenaline reaction. Acta Paediat. Scand., 54: 483 (1965).

21. Marliss, E. B., Wollheim, C. B., Blondel, B., Orci, L., Lambert, L., Stauffacher, W., Like, A. A., and Renold, A. E.: Insulin and glucagon release from monolayer cell 
cultures of pancreas from newborn rats. Eur. J. Clin. Invest., 3: 16 (1973).

22. Mrcka, M. A., Peake, G. T., Eaton, R. P. and Obenshain, S. S.: Ketotic hypoglycemia: A syndrome of gluconeogenic substrate deficiency. Pediat. Res., 6: 395 (1972).

23. Morgan, C. R., Sorensen, R. L., and Lazhrow, A.: Further studies of an inhibitor of the two antibody immunoassay system. Diabetes, 13: 579 (1964).

24. Mulifer, W. A., Faloon 1 , G. R., and Unger, R. H.: The effect of experimental insulin deficiency on glucagon secretion. J. Clin. Invest., 50: 1992 (1971).

25. Murphy, B. E. P.: Some studies of the protein-binding of steroids and their application to the routine micro and ultra-micro measurement of various steroids in body fluids by competitive protein-binding radioassay. J. Clin. Endocrinol., 27: 973 (1967).

26. Pagliara, A. S., Karl, I. E., De Vivo, D. C., Feigin, R. D., AND Krpnis, D. M.: Hypoalaninemia: A concomitant of ketotic hypoglycemia. J. Clin. Invest., 51: 1440 (1972).

27. Pagr.rara, A. S., Karl, I. E., Kenting, J. P., Brown, B. I., hNd Krpnrs, D. M.: Hepatic fructose-1, 6-diphosphatase deficiency. J. Clin. Invest., 51: 2115 (1972).

28. Pextremann, A., Favre, L., and Vallo'tron, M. B.: Effect of cold pressure test and 2-deoxy-D-glucose infusion on plasma renin activity in man. Eur. J. Clin. Invest., 2: 432 (1972).

29. Pohorecky, L. A., and Wurtman, R.: Adrenocortical control of epinephrine synthesis. Pharmacol. Rev., 23: 1 (1971).

30. Reid, I. A., Schrier, R. W., and Laurence, E. E.: An effect of extrarenal beta adrenergic stimulation on the release of renin. J. Clin. Invest., 51: 1861 (1972).

31. Sizonenko, P. C., Thrraz, M., Vallotton, M. B., Zahind, G., AND Paunier, L.: Assessment of adrenal medulla responsc to 2-deoxy-D-glucose in idiopathic hypoglycemia of childhood (Abstract). Eur. J. Clin. Invest., 2: 1307 (1972).

32. Thetze, H. U., Zurbrügg, R. P., Zuppinger, K. A., Joss, E. E., AND KäsER, H.: Occurrence of impaired cortisol regulation in children with hypoglycemia associated with adrenal medullary hyporesponsiveness. J. Clin. Endocrinol., 34: 948 (1972).

33. Unger, R. H., Ketterer, H., Dupré, S., and Eisentraut, A.: The effects of secretin, pancreozym, and gastrin on insulin and glucagon secretion in anesthesized dogs. J. Clin. Invest., 46: 630 (1967).

34. Vallotron, M. B.: Parallel radioimmunoassays of angiotensin I and of angiotensin II for measurement of renin activity and of circulating hormone in human plasma. Hormone Metab. Res., 4: 94 (1970).

35. VANDER, J. A.: Effect of catecholamine and the renal nerves on renin secretion in ancsthetized dogs. Amer. J. Physiol., 209: 659 (1965).

36. Wegienka, L. C., Grasso, S. G., anid Forsham, P. H.: Estimation of adrenomedullary rescrve by infusion of 2-dcoxy-Dglucose. J. Clin. Endocrinol., 26: 37 (1966).

37. Weisswange, A., Stauffacher, W., Balant, L., Burr, I. M., ANd Marliss, E. B.: Hormonal regulation of alanine metabolism in man: Effects of glucose and catecholamine infusions. Eur. J. Clin. Invest., 2: 312 (1972).

38. Wick, A. N., Drury, D. R., Nakad , H. I., AND Wolfe, J. B.: Localisation of the primary metabolic block produced by 2-deoxy-glucose. J. Biol. Chem., 224: 963 (1967).

39. Williamson, D. H., Lopes-Vierra, O., and Walker, B.: Concentrations of free glucogenic amino acids in livers of rats subjected to various metabolic stresses. Biochem. J., 104: 497 (1967).

40. Williamson, D. H., Mellanby, J., aNi Krebs, H. A.: Enzymic determination of $d(-)-\beta$-hydrobutyric acid and acetoacctic acid in blood. Biochem. J., 82: 90 (1962).

41. Wurtiman, R. J., ANd Axelrod, J.: Adrenaline synthesis: Control by the pituitary gland and adrenal glucocorticoids. Science, 150: 1464 (1965).

42. Sigma Chemical Co., St. Louis, Mo.

43. Novo Inclustri, Copenhagen, Denmark.

44. Made available through the Courtcsy of Dr. Roger H. Unger, Dallas, Tex.

45. Bochringer Mannheim, Gmbh, Mannheim, Germany.

46. We gratefully acknowledge the technical assistance of Mrs. A. M. Doret, D. Scholler-Markovic, M. Wyss, Misses B. Busslinger and B. Meier, Mr. D. Sourisseau, and the secretarial help of Miss C. Frésard and Mr. D. Furrer. We express our thanks to Dr. A. Rabinovitch and C. Wollheim, and to Miss M. Terraz, medical student, for their expert help, and to Professor A. E. Renold and Professor P. E. Ferrier for their critical suggestions and advice when preparing the manuscript.

47. Presented in part at the Annual Meeting of the European Socicty for Pediatric Rescarch, Hcidelberg, Germany, September 11-14, 1972. Supported by grants nos. 3.384.70, $3.414 .70,3.427 .70$, and 3.487 .70 from the National Swiss Foundation for Scientific Rescarch.

48. The present address of Dr. E. B. Marliss is: Department of Medicine, University of Toronto, Toronto, Ontario, Canada.

49. Requests for reprints should be addressed to: Pierre C. Sizonenko, M.D., Clinique Universitaire de Pédiatrie, 30, Bd de la Cluse, 1211 Geneva 4, Switzerland.

50. Accepted for publication August 3, 1973. 